money by publishing in this field without much regard to genuine need; but that temptation imposes a greater, not a lesser, responsibility on publishers and editors to attempt to fulfil a useful role.

In so far as we are doing a good job, I hope the medical profession is now more willing to accept the free medical press. If we are not yet earning our keep, then ultimately only the profession has the power to insist on a better standard, both by its criticism and by greater involvement.

\section{Postlude}

I welcome the opportunity to set on paper some facts and some thoughts about the free medical press, because considering the size of the phenomenon it is remarkably little recorded. The few references in formal journals in recent years have been disappointingly inaccurate, especially in view of the vast amount of information privately available to publishers, advertising agencies, and pharmaceutical companies.

I have given only the most superficial summary of such information-for example, on finances and readership evaluation. There is much, much more which comprises the daily work of hundreds of people. Yet even the barest facts may be fresh to the public view-and they should be better known. For there is a danger that this gigantic publishing, advertising, and medical phenomenon will continue to go unrecorded, and, more important, uninfluenced during its progression by the group of people to whom it should be of the highest importance-the medical profession.

\title{
The role of television
}

\section{KARL SABBAGH}

The scene, an operating theatre. A surgeon is surrounded by green-gowned figures. $\mathrm{He}$ is about to perform a heart transplant operation and asks one of the figures which of them would like to make the first incision. No one volunteers so the scalpel is handed to one of the reluctant bystanders. "You do it. You're from Guy's aren't you ?"

"No Sir, Sunday Times, actually, I'm writing an article about the operation."

The surgeon offers the scalpel to another figure, who eagerly prepares to make the incision until he is identified as the Sunday Times photographer. One by one, the other participants around the table are identified as a man from "World in Action" and a correspondent from Caravanning and Camping. Finally, the patient sits up and announces that she is ITN reporter from "News at Ten."

It is all good harmless fun and actually a sketch from BBC TV's "Not the Nine O'Clock News." However, a topic has come of age when it can be parodied in a television comedy programme. The reality is recognisable enough by a wide range of people for a good parody to arouse a reaction.

Medicine and the media, particularly the broadcast media, have become linked. Each has something to say about the other, and neither utterance is usually complimentary. The media accuse doctors of complacency, authoritarianism, self-interest, and organ grabbing, while doctors see the media professionals as irresponsible, sensationalising, trivialising, and superficial. However much medical criticism of the broadcast media directs its attention towards the content of programmes, the impression is often given that it is the medium itself that is under attack. The suggestion is that the act of presenting images and sounds of real people saying and doing things to be witnessed in every home in the nation is somehow reprehensible in itself, particularly when applied to medicine. I do not propose to pursue the merits of that case in this article, since it is not central to my theme. It is, however, relevant. If television is to contribute to the future of medical communication it will do so initially against a background of prejudice and ignorance. Many doctors do not watch television, or say they do not, but are very certain about

MSD Foundation, London WC1

KARL SABBAGH, director what is wrong with it. How then can they be persuaded that it does have some uses in their own field and that it will be of increasing value to them in the future?

\section{Education, information, and entertainment}

Let us first look at the purpose of medical communication. Printed medical communications have several purposes. Firstly, there is the placing on record of original research or hypotheses. Secondly, there is the review of progress in various medical fields, served very well by the sort of leaders that the $B M \mathcal{F}$ and the Lancet produce. Thirdly, there is the continuing presentation of views from doctors in practice about their experiencesexperiences which they feel will benefit others by being shared. This may sometimes contain original research but not necessarily. Fourthly, there is communication in the political field. This sort of coverage occurs in the $B M \mathcal{F}$ obviously, as the organ of the BMA, but is also a staple part of other medical newspapers and journals such as General Practitioner. Fifthly, there is the more traditional type of journalism as applied to medicine in which, on a basis of interviews and observations made by a particular writer, a report is presented which summarises some aspect of modern medical practice in a way which is readable and entertaining. At its broadest these types of communication can be summarised as education, information and, even for doctors, entertainment.

Can the special qualities of television be used to enhance the effectiveness of any of these types of medical communication? I use the word "television" to cover the increasing use of nonbroadcast video techniques. As the applications of video technology grow, the gap between broadcasting, the BBC and ITV, and "narrowcasting," the use of video cassette machines to record and play back, will close. Already in the domestic field, what appears on your television set might be being transmitted at the time from a transmitter or could be coming from a video cassette of a television programme recorded yesterday or last week; it could be from a video cassette hired or bought from a shop and showing a film that has never been seen on television; or it could be some specialist video material specially prepared for your own interests by a company set up to use this new medium in the same way that publishers use printing. Indeed, your screen may also be presenting images and text that have never existed in reality but as computer-generated signals on Prestel, Oracle, or Ceefax. 


\section{A different way of communicating}

In a sense, whether the material is recorded or live, cassette or disc, closed circuit or broadcast, is irrelevant. The essential characteristic of television is that it can preserve or transmit information as moving pictures and sound. Compared with the conventional medical communication system of printed words and pictures this in turn implies a different means by which we appreciate the information presented to us, and that implies a different type of processing in our minds.

Does this different type of communication provide opportunities or possibilities that cannot be achieved by conventional methods or does it just provide a superficially different means of using the same communication channels? When I look at some attempts to use television for medical communication it seems that there is little advantage over a printed article. A speaker reciting a prepared script on some factual topic, with occasional graphs or simple diagrams really has nothing to offer over a printed version with the same content. Even an unscripted interview between a so-called "expert" and a deferential interviewer can end up contributing little more to the audience's knowledge than a side or two of A4 typescript, readable in a minute and a haif.

If medical communication in the future is going to make use of television methods, and I believe it will, the communicators must pay some attention to the particular values that video shares with no other medium. Those come down to two essential factors: the ability to show movement; and the ability to demonstrate human communicating behaviour. It may seem that there are comparatively few aspects of modern or future medical communication that can only be achieved using those properties of the medium. Major or minor surgical procedures, perhaps, examination techniques, specialised diagnostic techniques-these require the showing of movement; non-verbal communication, the doctor-patient relationship, medical history taking-these need to be seen to be telieved.

With a few exceptions, there is little sign that even in these obvious areas the best use is being made of the medium. This is not always the fault of that small and dedicated band of enthusiasts, the video freaks. These are doctors who make a valiant attempt to produce homegrown video programmes against all sorts of financial and attitudinal barriers. Such television material can actually pioneer techniques which never get taken up and exploited by professionals, but it can be seen by colleagues as doctors playing about, rather than as a new tool for teaching and communication. Support for audiovisual equipment or staff is difficult to come by in some regions, and when equipment does exist it is often out of date and difficult to find. I once visited a model postgraduate centre to show some video material and found that no one knew where the video recorder was. Eventually, after telephone calls to the tutor's secretary, who was having a day off, it was tracked down to a cupboard in the pathology museum, which turned out to be an appropriate comment on the state of that particular cassette recorder.

\section{Techniques misused}

Even when material is prepared by audiovisual or medical illustration departments of universities or hospitals it often lacks any imaginative input. Such material often consists of recordings of lectures that were taking place anyway or interviews with visiting professors containing facts which could have been read up in a quarter of the time taken to look at the video tape. What is often missing in this sort of material is an input from people with expertise in the medical area who are willing to develop similar expertise in the production of audiovisual material. This peculiar kind of hybrid is still rather hard to find and yet without such collaboration television techniques are never going to be used to best advantage.

In the area of professionally produced television material for doctors the situation is not much better. Again, we have little true collaboration between doctors and producers, with both groups misunderstanding or mistrusting the other. In the nonbroadcast area the major source of original medical video material 3 is pharmaceutical companies, which on the whole produce $\mathbb{\unrhd}$ unexceptional, conventional programmes which make many of $c$ the mistakes I have already mentioned. With few exceptions, $\widehat{\widehat{O}}$ and one of them is the organisation for which I work, the choice $\bar{F}$ of subject matter is inevitably related more or less to the aims $\prod_{\mathbb{D}}$ of the company making the material, and since those aims are $\infty$ often to sell more drugs the content of professionally produced medical television is often very haphazard. Instead of looking at the field of medical television as a whole and deciding what is needed, a programme production unit will find itself producing material on topics which are set by priorities far away from the $\overline{0}$ needs and interests of potential viewers. There are few indepen- $\overline{\frac{N}{5}}$ dent production units willing to produce non-promotional- $\mathbb{\Phi}$ that is, unsubsidised-educational or informational television material.

Part of the problem relates to the difficulties of sales and $\overrightarrow{0}$ distribution of television material in the non-broadcast area. $\vec{\overrightarrow{ }}$ Producing even the simplest medical video cassette to a technical ${ }_{\sigma}$ standard capable of generating hundreds of copies and to a $\bar{O}$ production standard where it will not be laughed off the screen is an expensive business. It is not unusual for a company to spend $£ 20000$ to $£ 25000$ on a 30 -minute video or film produc- $\leftrightarrow$ tion. Since these costs are of the same order of magnitude as an $\mathscr{E}$ advertising campaign, for example, it is not unreasonable for pharmaceutical companies to spend some of their money in this way.

Any other potential producer of medical television pro- $\frac{}{2}$ grammes for non-broadcast distribution is going to see these $\overrightarrow{0}$ figures in a very different light. $\mathrm{He}$ is going to have to be con- $c$ vinced that the topic and the way it is presented are going to be of enough interest to achieve sales figures that will recoup all $\vec{\theta}$ the production costs.

\section{Communication in action}

If I am so critical of the present uses of television in medical

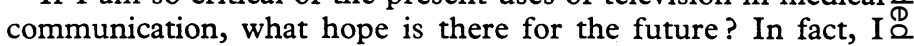
would not be here if I did not have some faith in the innate good $\overrightarrow{0}$ sense and vision of the medical profession. And even if the 3 medical profession does not have good sense and vision it is a great follower of fashion, as the history of medical treatments and the promotional activities of pharmaceutical companies show. I sense that the balance between diehards and visionaries is already changing so far as television is concerned. More and more people whose business is medical communication see that 3 television methods make it possible to communicate in a unique way. I have mentioned already the ability to show human communication in action, and this, I believe, is the key to a major use of television in the future.

There is first the ability to present material on those aspects $\tilde{\sigma}$ of the doctor's job that depend on his personality, verbal skills, $\rightarrow$ problem-solving abilities, examination techniques, and counselling skills. This is a growing area and one in which television $N^{\circ}$ is already showing itself very useful. But more important than $\mathbb{C}^{-}$ that is an area which I think will actually supersede the behavioural side - the ability to see and hear individual doctors from all specialties, talking about their ideas across the board $\frac{}{\Phi}$ from therapeutics to politics. In the end, all printed material, the major source of medical information at the moment, is 0 written by humans. In the past, the printed word has inspired a type of reverence among readers: "It must be true, I read it $\stackrel{\mathbb{D}}{\mathscr{D}}$ somewhere." This unhealthy respect for print is breaking down. $\stackrel{\mathbb{Q}}{\mathbb{2}}$ Some years ago, The Times started naming the writers of its news stories, breaking a habit of a century and a half. More recently the $B M \mathcal{F}$ has abandoned anonymity in its leading 0 articles, preferring to name the individuals responsible for the views put forward. This was presumably so that the reader could use his knowledge of the antecedents and interests of the $P$ 
writer to help decide how much reliance to put on the content and to know whom to challenge if he disagreed. These small signs indicate the human roots of medicine and point to a time when we will be forced to take into account all available information about the presenter of views or scientific results.

If therefore we could see and hear the individual, or team, whose experimental work we have been reading about; if perhaps we could hear somebody ask the questions we would like to ask, and see the way in which the answers were given, would this not be a valuable extra source of information to use in assessing whether or not to rely on these new data ? I am not just talking about slickness versus hesitation-the polished performance compared with amateur bumbling. I am talking about the quality of the thought processes that have led up to the forming of opinions, the marshalling of facts, and the weighing of evidence-often both polished performer and bumbler can betray a sad lack of all these qualities. Across the whole field of medical communication an ability to assess these qualities in an individual could become an increasingly important aspect of communication. Where this will be particularly useful, of course, is in the area of medical politics. While the printed $B M \mathcal{F}$ Supplement may be an acquired taste, a television version, accompanied by lively and perceptive questioning of medical politicians, might well rouse doctors to act in all sorts of useful if unpredictable ways.

Even in areas such as straight scientific reporting of new data, a television presentation, in summary form, with the researcher's conclusions, visual treatment of his data, and personal comments by members of his team, could enable far more doctors to understand, assimilate, and retain the essential message of material that may seem daunting in its full form on the printed page.

The role I am suggesting for the use of medical television is one of enhancing understanding of issues which may well be inadequately understood at the moment because of the sheer volume of print that is currently being produced in the medical field. So far, I have talked about non-broadcast television material, but, of course, it is possible that increasing use can be made of broadcast television if a truce is declared between television producers and doctors. Unfortunately, a year and a half after the Panorama programme on brain death there are still antibodies circulating among doctors which result in a level of suspicion and a lack of interest in co-operation. I believe that there can be much greater co-operation between doctors who see the potential of broadcast television and producers who are willing to believe that they do not know everything about the subject.

\section{Doctors and laymen}

I do not believe, however, that there are major new uses in the future of television to a general audience, other than one which $i$ personally am not very enthusiastic about-so-called health education. Certainly some determined policy on the part of the Government or indeed, of a television company, could result in much more material being broadcast in the area of health education. Unfortunately, health education material is not widely appreciated by the public at the moment, and even when it is watched the evidence for its effectiveness is hard to come by, as the "Granada Reports" anti-smoking series of a few years ago showed. I do not think the remedy for this lack of effectiveness is to transmit more material, and if health education is to appear on television it must almost be a byproduct of programmes made on topics which are interesting in their own right, rather than as part of a planned campaign by some central authority which thinks it knows what is good for people. Television will lose its credibility if it is seen as the servant of particular professional interests, however laudable those interests might be.

The danger with using the medium for a purpose like health education is that the people who then plan that use are likely to be enthusiastic protagonists of approaches which may turn out later not to have the value that was initially foreseen. There are several measures which have been recommended in the past on the basis of their supposed power to prevent disease which further scientific assessment has shown to be overoptimistic. The current state of disarray over dietary recommendations for heart disease or the lack of evidence of the effectiveness of screening for breast cancer in women under 50 are two examples of topics which if presented too uncritically a few years ago might have led to disillusionment and distrust in the public now.

Where I believe television does have a continuing role in communication between doctors and laymen is in its ability to report to the public as honestly as possible the issues that affect them as they are being discussed, rather than after decisions have been made. Such reporting does already take place but is often prepared by journalists or producers who are not themselves as well-informed of the issues as we have a right to expect. It was not the decision to make a programme on brain death and organ transplants that was wrong; but it was very wrong to misunderstand and neglect the real issues in the way that Panorama did. But better informed producers depend on the suppliers of the information, and that means more collaboration with doctors rather than less.

This projected increase in medical television may sound improbable to those who have a television set only for the children or the servants. I am, however, talking about a future in which there will be as many homes with video recorders as there are today homes with colour television sets. These will be homes in which the normal pattern of broadcast television will have changed, with less emphasis on peak-time transmission since cassette recording will enable any programme to be watched at any time after it has been recorded. They are homes into which prerecorded video cassettes will come from a variety of sources connected with leisure and education, and where specialist medical video material will not be out of place. And those cassettes will be considerably smaller, and cheaper, than the current modest six or seven pounds an hour.

All these factors will make television as natural a means of publishing as print is now, for specific purposes. And in some indefinable way, because television is at its most useful when showing human behaviour, I think that its increasing use in medical communication will make medicine more human too.

What is known about immunity in malaria?

Susceptibility to malaria is influenced by genetic factors. Resistance to infection with Plasmodium vivax is associated with the absence of Duffy blood group antigens on erythrocytes (genotype Fy-Fy), ${ }^{1}$ while individuals heterozygous for the sickle cell $(\mathrm{HbS})$ gene are partially resistant to $P$ falciparum malaria. ${ }^{2}$ In susceptible subjects malaria induces changes in macrophage and lymphocyte (T- cells and B-cells) populations and the production of specific antibodies affecting IgG, IgM, and IgA. ${ }^{3}$ Where malaria is highly endemic protective immunity evolves slowly in response to repeated infection and rarely becomes total. Protection has been transferred passively between people in the IgG fraction of immune serum, and the transplacental acquisition of protective antibodies by the fetus is a widely accepted explanation for the rarity of congenital malaria in holoendemic regions. Experimentally in animals, the passive transfer of immunity by means of serum-free splenic cells from an immune donor has been achieved, showing that protection may be mediated by cellular as well as humoral mechanisms. Animals have been effectively immunised by vaccines using sporozoites, asexual erythrocytic stages, or gametes, and the resultant immunity shown to be both species- and phase-specific.-IAN A MCGREGOR, professorial fellow, Liverpool School of Tropical Medicine.

${ }^{1}$ Miller LH, McGiniss MH, Holland PV, Sigmon P. The Duffy blood group phenotype in American blacks infected with Plasmodium vivax in Vietnam. Am Trop Med Hyg 1978;27:1069-72.

Luzatto L. Genetic factors in malaria. Bull WHO 1974;50:195-202.

Cohen S. Immunity to malaria. Proc $R$ Soc Lon B 1979;203:323-45. 